\title{
Biosynthesis and Characterization, Antioxidant and Antimicrobial Activities of Selenium Nanoparticles from Ethanol Extract of Bee Propolis
}

Shubharani R, Mahesh M and V.N.Yogananda Murthy*

Department of Biotechnology, Azyme Biosciences Pvt. Ltd, Bengaluru, Karnataka, India

\section{Abstract}

Aim: Biosynthesis of selenium nanoparticles (SeNPs) has gained significant interest due to their distinctive chemical and biological properties that is essential for potential application in various fields.

Methods: In the present study, propolis, the beehive product collected from 5 different Indian states like Haryana, Himachal Pradesh, Uttaranchal, Karnataka and Kerala were used for the biosynthesis of SeNPs and characterized by using UV-vis spectrophotometer, fourier transform spectroscopy (FT-IR), X-ray diffraction (XRD) and scanning electron microscopy (SEM)

Results: SeNPs biosynthesized by propolis were observed as crystalline, oval shaped and smooth surface particles. Study also reports the efficiency of 2,2'-azino-bis (3-ethylbenzothiazoline-6-sulphonic acid) (ABTS), 2,2-diphenyl-1picrylhydrazyl (DPPH), Fluorescence recovery after photobleaching (FRAP) and superoxide dismutase (SOD) assay to estimate the antioxidant potential. The antimicrobial assay was evaluated only for SeNPs synthesized from propolis extracts obtained from Karnataka state showed high antioxidant activity. The antibacterial activity against pathogenic gram-positive bacterial strains (Staphylococcus aureus, Bacillus cereus and Streptococcus mutans), gram-negative bacterial strains (Escherichia coli, Salmonella typhi and Pseudomonas aeruginosa) was evaluated by resazurin microtiter plate method to check the minimum inhibition concentration (MIC). The antifungal activity of pathogenic fungi such as Aspergillus niger, Aspergillus flavon and Candida albicans were determined by well diffusion method.

Conclusion: It is the first report describing the biosynthesis of selenium nanoparticles using bee propolis. This study demonstrated the antioxidant and antimicrobial potential of SeNPs biosynthesised by using ethanol extract of propolis.

Keywords: Antibacterial; Antifungal; Bee propolis; Biosynthesis; Nanoparticles; Selenium

\section{Introduction}

Biosynthesis of nanoparticles is an interdisciplinary application of metal science and technology through biology. The main reaction of this technique is oxidation or reduction using biomolecules [1]. The metal nanoparticles with a definite shape, size, and crystal nature have a considerable application in medicine including cancer therapy [2], DNA analysis [3], drug delivery [4], biosensor [5] and magnetic resonance imaging [6], apart from agricultural [7], environmental remediation [8], pharmaceutical [9], electronics and commercial industries [10]. Currently, the development of biocompatible nanoparticles is of great concern among the scientists worldwide, because of their unique physical, chemical and biological characteristics [11]. To overcome the limitations like the generation of hazardous toxic chemicals from the conventional methods, biological processes have been considered as an alternative and efficient method for the nanoparticles synthesis, that exhibits significant electromagnetic and catalytic property, large surface to volume ratio, less toxic and cost-effective $[12,13]$.

Selenium is a non-metallic essential trace element exists in three well defined allotropic forms such as red coloured amorphous selenium in powder form, black in coloured crystalline trigonal having helical chains and crystalline monoclinic $(\alpha, \beta, \gamma)$ is also red in colour [14]. Selenium as a micronutrient at an appropriate concentration is essential for human health due to its antioxidative effect. Selenium deficiency can lead to heart disease, hypothyroidism and a weakened immune system [15]. It is reported that SeNPs have excellent biocompatibility, bioefficacy and low toxicity as compared to various organic and inorganic forms of selenium compounds [16]. The biosynthesis of SeNPs has gained much interest due to its excellent therapeutical and nutraceutical potential among the other nanoparticles [17-19]. Biosynthesis of SeNPs, using the diverse range of microorganisms [20] and different plant parts including leaves, flower, fruits, peel and seed extracts have been studied extensively $[21,22]$. However, there are no reports on the biosynthesis of SeNPs from bee propolis that are widely used in folk medicine since ancient time.

Propolis is a natural resinous beehive product collected by honey bees from leaf buds and exudates of various plants, mixed with bee enzyme, pollen and wax. Its complex bioactive compounds depend on plant sources in local flora and exhibit a broad spectrum of biological and pharmacological properties [23]. It was reported that bee propolis can synthesize nanoparticles, due to its broad range of biomolecules like phenols, flavonoids, alkaloids, steroids, terpenoids etc. [24,25]. In this study, the ethanol extract of bee propolis collected from different states of India has been used to evaluate its antioxidant potential and the extract of bee propolis collected from Karnataka was used as reducing, capping, and stabilizing agent for the biosynthesis of SeNPs and its antimicrobial activity.

*Corresponding author: V.N.Yogananda Murthy, Department of Biotechnology, Azyme Biosciences Pvt. Ltd, Bengaluru, Karnataka, India, Tel: 919880091635 E-mail: dryoganand16@gmail.com

Received: December 17, 2018; Accepted: February 11, 2019; Published: February 15, 2019

Citation: Shubharani R, Mahesh M, V.N.Yogananda Murthy (2019) Biosynthesis and Characterization, Antioxidant and Antimicrobial Activities of Selenium Nanoparticles from Ethanol Extract of Bee Propolis. J Nanomed Nanotechnol 10 522. doi: 10.4172/2157-7439.1000522

Copyright: (c) 2019 Shubharani R, et al. This is an open-access article distributed under the terms of the Creative Commons Attribution License, which permits unrestricted use, distribution, and reproduction in any medium, provided the original author and source are credited. 
Citation: Shubharani R, Mahesh M, V.N.Yogananda Murthy (2019) Biosynthesis and Characterization, Antioxidant and Antimicrobial Activities of Selenium Nanoparticles from Ethanol Extract of Bee Propolis. J Nanomed Nanotechnol 10: 522. doi: 10.4172/2157-7439.1000522

Page 2 of 7

\section{Materials and Methods}

Fresh propolis sample belonged to Apis mellifera colonies were collected from 5 states like Haryana, Himachal Pradesh, Uttaranchal, Karnataka and Kerala in India. The samples were cleaned to remove the debris and extracted with $70 \%$ ethanol for further investigations [26].

\section{Antioxidant assay}

The antioxidant potential of ethanol extracts of propolis samples collected from 5 different states of India were used.

\section{ABTS free radical-scavenging activity}

ABTS radical scavenging was carried out by the reaction of ABTS $(7 \mathrm{mM})$ solution in different aliquots of ethanol extracts $(100,200$, $300,400,500 \mu \mathrm{g} / \mathrm{ml})$. After the incubation in dark for $15 \mathrm{~min}$, extent of decoloration was measured at $734 \mathrm{~nm}$. ABTS reagent without sample was used as control. Percentage of ABTS radical inhibition was plotted against gallic acid and $\mathrm{IC}_{50}$ values were determined [27].

\section{DPPH free radical scavenging activity}

DPPH scavenging activity was estimated by addition of different concentration of ethanol extracts to $0.1 \mathrm{mM}$ of 1-1-diphenyl-2picrylhydrazyl in methanol. The solution was incubated in dark at $37^{\circ} \mathrm{C}$ for $30 \mathrm{~min}$ and change in absorbance was measured at $517 \mathrm{~nm}$ using spectrophotometer. Percentage of DPPH free radical scavenging activity of each concentration was calculated and $\mathrm{IC}_{50}$ values were determined [28].

\section{FRAP assay}

Different concentrations $(100-500 \mu \mathrm{g} / \mathrm{ml})$ of ethanol extracts were separately mixed with FRAP reagent and allowed to react at $37^{\circ} \mathrm{C}$ in dark for $30 \mathrm{~min}$. An increase in the absorbance with increasing concentration is directly proportional to the reducing power of samples. Results expressed as the concentration of samples having ferric-tripyridyltriazine reducing ability in gallic acid was assessed by measuring the absorbance at $593 \mathrm{~nm}$ with some modifications [29].

\section{Superoxide dismutase (SOD) activity}

In this assay, the reaction mixture containing $250 \mathrm{mM}$ phosphate buffer ( $\mathrm{pH} 7.8)$, EDTA $(0.1 \mathrm{mM})$, NBT $(75 \mu \mathrm{M})$, methionine $(13 \mathrm{mM})$ and riboflavin $(2 \mu \mathrm{M})$ was mixed with different concentrations of ethanol extracts and incubated at room temperature for $15 \mathrm{~min}$, absorbance was measured at $560 \mathrm{~nm}$. Inhibition percentage of superoxide anion generated was calculated [30].

\section{Biosynthesis of SeNPs from ethanol extract of propolis}

The highest antioxidant activity was observed in propolis extract collected from Karnataka state and used for the biosynthesis of SeNPs. In this process, $10 \mathrm{ml}$ of freshly prepared ethanol extract was added drop wise to $30 \mathrm{mM}$ sodium selenite solution, along with $40 \mathrm{mM}$ ascorbic acid. The mixture was allowed to react at room temperature for $24 \mathrm{hrs}$ till the colour changes from light brown to orange. The biosynthesised SeNPs were centrifuged at $10,000 \mathrm{rpm}$ for $30 \mathrm{~min}$ at $4^{\circ} \mathrm{C}$ and then the separated nanoparticles were washed thrice with double distilled water. The nanoparticles were then washed by using ethanol and dried overnight. The powder form of SeNPs was used for further characterization and analysis [31].

\section{Characterisation of selenium nanoparticles}

UV-vis spectrum analysis: UV-vis spectrum is the most important technique for identification and characterization of nanoparticles. The wavelength of biosynthesised SeNPs was recorded from 200-800 nm using Genesys 10S UV-visible spectrophotometer and analysed for the maximum absorption peaks.

Fourier transform infrared spectroscopy analysis: FT-IR spectrum was obtained using spectrophotometer (Shimadzu-00463 model) in the spectral region of $4000-600 \mathrm{~cm}^{-1}$ using a resolution of $4 \mathrm{~cm}^{-1}$ and 64 coadded scans. FT-IR spectrum confirms the surface chemistry and organic functional group responsible for stabilization of nanoparticles [32].

$\mathrm{X}$-ray diffraction analysis: $\mathrm{XRD}$ reading was taken on a Bruker $\mathrm{D} 8$ Advanced Eco X-ray diffractometer having Bragg-Brentano Focusing geometry. XRD data was analyzed using X'pert high score software for the identification of the crystalline phases. X-ray diffraction is used for the phase identification and structure of nanoparticles [33].

Scanning electron microscopy analysis: A Hitachi (Model SU 3500) ultrahigh resolution field emission scanning electron microscope was used to observe the morphological characteristics and size of biosynthesised SeNPs [34].

\section{Antimicrobial assay}

Antimicrobial assay was evaluated only for the SeNPs biosynthesised from propolis extracts obtained from Karnataka. The antibacterial activity against pathogenic gram-positive bacterial strains (Staphylococcus aureus, Bacillus cereus and Streptococcus mutans) and gram-negative bacterial strains (Escherichia coli, Salmonella typhi and Pseudomonas aeruginosa) were evaluated by resazurin microtiter plate method to check the minimum inhibition concentration. Antifungal activity of pathogenic fungi such as Aspergillus niger, Aspergillus flavon and Candida albicans were determined by well diffusion method $[35,36]$.

Antibacterial assay by resazurin microtiter plate: Resazurin microtiter plate method was used to study the antibacterial activity of the biosynthesised SeNPs. Resazurin solution (10\%) was prepared in sterile water, stored at $20^{\circ} \mathrm{C}$ as a stock solution and diluted to $1: 10$ with sterile water when required. In each well of the microtiter plate, $100 \mu \mathrm{l}$ of sterilized Luria Bertani (LB) broth, $30 \mu \mathrm{l}$ of $0.1 \%$ resazurin solution, $100 \mu$ of serially diluted biosynthesized SeNPs (1000, 500, $250,125,62.5,31.25,15.25,7.81 \mu \mathrm{g} / \mathrm{ml}$ ) was added. Subsequently, 100 $\mu \mathrm{l}$ of each bacterial culture was inoculated and $200 \mu \mathrm{l}$ of deionized water was added to prevent the sample from drying. The control wells were prepared with culture media, resazurin dye, and bacterial suspension. Color blank wells were prepared only with broth and dye. The plates were sealed and incubated for $24 \mathrm{hrs}$ at $37^{\circ} \mathrm{C}$. After incubation, the color change from blue to pink was observed, whereas blue colored wells with no growth of organisms, pink and orange colors were positive with growth of organisms.

Antifungal assay by well diffusion method: Well diffusion method was applied to study the antifungal activity of biosynthesised SeNPs from propolis extract. Fungal inoculums of Aspergillus niger, Aspergillus flavous and Candida albicans were spread thoroughly on the sterilized petriplates with solidified potato dextrose agar media. On each agar plates, five wells with $5.5 \mathrm{~mm}$ diameter were made using sterile cork borer. The wells were filled with $50 \mu \mathrm{l}$ of different concentrations of sample. Standard fungicide cycloheximide used as positive control and ethanol used as a negative control. The culture plates were incubated at $25^{\circ} \mathrm{C}$ for $72 \mathrm{hrs}$ and the zone of inhibition for all the three organisms was measured in diameter $(\mathrm{mm})$ around the wells. 
Citation: Shubharani R, Mahesh M, V.N.Yogananda Murthy (2019) Biosynthesis and Characterization, Antioxidant and Antimicrobial Activities of Selenium Nanoparticles from Ethanol Extract of Bee Propolis. J Nanomed Nanotechnol 10: 522. doi: 10.4172/2157-7439.1000522

Page 3 of 7

\section{Statistical analysis}

The experiment was conducted in triplicates and the results were statistically analysed. All the standards were calculated by regression value and Pearson's correlation is less than 0.05 .

\section{Results}

\section{Antioxidant activity}

The antioxidant potential of ethanol extracts of propolis collected from the different locations of India was measured by ABTS, DPPH, FRAP and SOD assays.

\section{ABTS assay}

ABTS radical cation scavenging activity is an excellent method to determine the antioxidant capacity of the samples, which has the characteristic absorbance maxima at $734 \mathrm{~nm}$. In the results, ethanol extracts showed a significant ABTS radical scavenging activity. Among all the samples, the propolis collected from Karnataka exhibited highest activity with $\mathrm{IC}_{50}$ value of $15.1 \mu \mathrm{g} / \mathrm{ml}$, which was comparable with the standard gallic acid. The antioxidant activity of ethanol extracts is represented in Figure 1A.-

\section{DPPH assay}

DPPH (1-1-diphenyl-2-picrylhydrazyl) was used to measure the free radical scavenging activity which was stable at room temperature and accepts electron or hydrogen free radical to form a stable diamagnetic molecule. This ability of DPPH to undergo reduction by an antioxidant is measured in terms of decrease in its absorbance at $517 \mathrm{~nm}$. Maximum free radical scavenging activity was determined by the sample collected from Karnataka with $\mathrm{IC}_{50}$ value of $78.9 \mu \mathrm{g} / \mathrm{ml}$ followed by Uttaranchal $(217.2 \mu \mathrm{g} / \mathrm{ml})$, Kerala $(223.5 \mu \mathrm{g} / \mathrm{ml})$ and Haryana $(263.8 \mu \mathrm{g} / \mathrm{ml})$. The minimum activity was recorded from Himachal Pradesh sample with $358.2 \mu \mathrm{g} / \mathrm{ml}$ of $\mathrm{IC}_{50}$ value. The results of $\mathrm{DPPH}$ radical scavenging activity of ethanol extracts is represented in Figure 1B.

\section{FRAP assay}

FRAP is a simple assay that measures the ability of antioxidants to reduce the ferric 2,4,6-tripyridyl-S-triazine complex (TPTZ-Fe (III)) to blue coloured ferrous complex (TPTZ-Fe(II)) in acidic medium. All the ethanol extracts tested exhibited higher antioxidant capacity and the $\mathrm{IC}_{50}$ values ranged from $2.86 \mu \mathrm{g} / \mathrm{ml}$ (Karnataka) to $5.71 \mu \mathrm{g} /$ $\mathrm{ml}$ (Himachal Pradesh). The potential antioxidant activity of ethanol extracts are presented in Figure 1C.

\section{SOD assay}

Superoxide is a highly reactive toxic species, induces oxidative damages in the living system. The reduction of riboflavin generates superoxide radical which reduced NBT, resulting in the formation of

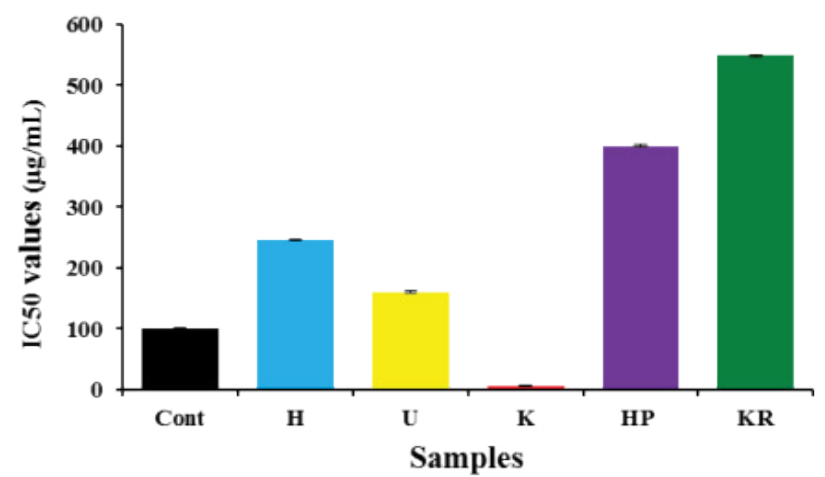

ABTS assay (A)

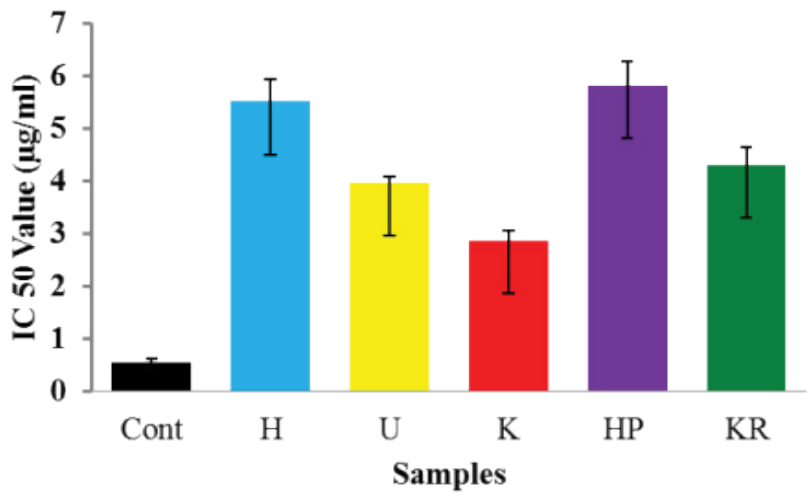

FRAP assay (C)

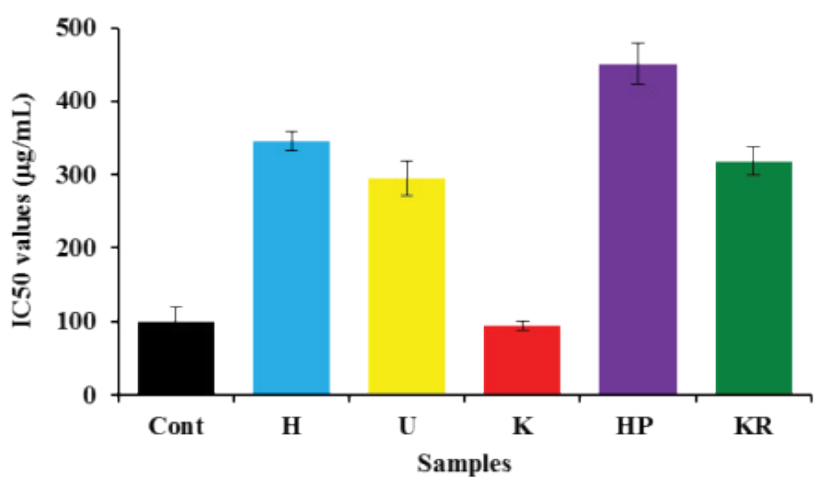

DPPH assay (B)

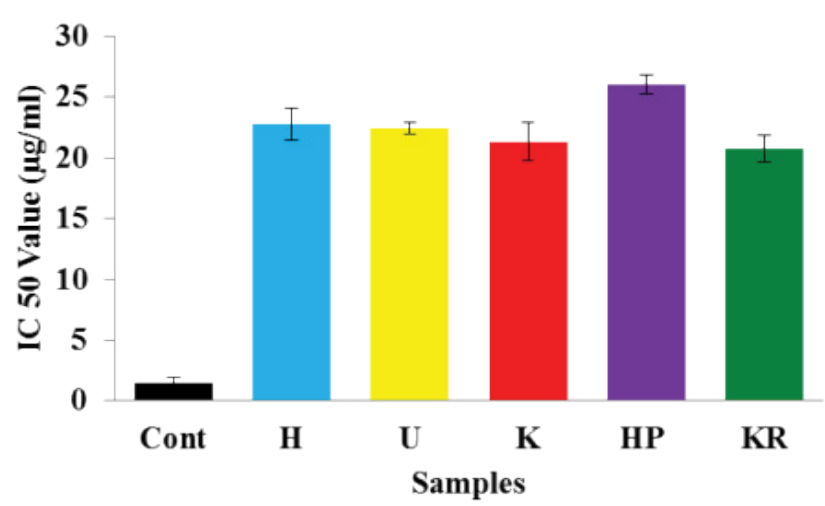

SOD assay (D)

Figure 1: Free radical scavenging activity of ethanolic extract of bee propolis samples. (Cont-Control; H-Haryana; U-Uttaranchal; K-Karnataka; HP-Himachal Pradesh; KR-Kerala). 
Citation: Shubharani R, Mahesh M, V.N.Yogananda Murthy (2019) Biosynthesis and Characterization, Antioxidant and Antimicrobial Activities of Selenium Nanoparticles from Ethanol Extract of Bee Propolis. J Nanomed Nanotechnol 10: 522. doi: 10.4172/2157-7439.1000522

Page 4 of 7

blue formazine. The inhibition of formazine was maximum in extracts collected from Karnataka with IC $_{50}$ value of $21.65 \mu \mathrm{g} / \mathrm{ml}$ followed by Kerala $(22.22 \mu \mathrm{g} / \mathrm{ml})$, Uttaranchal $(22.32 \mu \mathrm{g} / \mathrm{ml})$, Haryana $(22.52 \mu \mathrm{g} /$ $\mathrm{ml})$ and Himachal Pradesh $(25.91 \mu \mathrm{g} / \mathrm{ml})$. Gallic acid was used as positive control in the entire antioxidant assay. The superoxide radical scavenging assay of propolis samples are presented in Figure 1D.

\section{Biosynthesis of selenium nanoparticles}

The reduction of selenium ions into SeNPs induced by propolis extracts was evident by change in color from light brown to reddish orange, which is the most significant property of nanoparticles. The ethanol extract of propolis from was brown in color and after the addition of acidic sodium selenite solution, color changed to orange within $24 \mathrm{hrs}$ indicating the formation of SeNPs.

\section{Characterization of selenium nanoparticles}

The characteristics of nanoparticles such as size, structure and shape are essential for the determination of particles property. There are a number of methods to characterise the biosynthesised nanoparticles among which UV-visible spectrophotometry, Fourier transform infrared, X-ray diffraction and Scanning Electron Microscopy are widely used.

\section{UV-vis spectrum analysis}

UV-vis spectrum of SeNPs biosynthesised from ethanol extract of propolis is shown in Figure 2. The absorbance spectrum was recorded in the range of $200-800 \mathrm{~nm}$. A strong absorption peak was observed between $250-280 \mathrm{~nm}$ with maxima at $265 \mathrm{~nm}$, confirming the presence of selenium in the samples.

\section{FT-IR analysis}

FT-IR spectra of SeNPs are presented in Figure 3 and results showed the peak value around 2950 and $2850 \mathrm{~cm}^{-1}$ may be due to the presence of organic polymer lignin. The absorption peak around 1750 and 1470 $\mathrm{cm}^{-1}$ can be the peak of carboxyl group. The peak at 1030 and $730 \mathrm{~cm}^{-1}$ represent phenolic group. Spectra confirmed the presence of different functional group like alcohol and polyphenols, may be responsible for reduction and stabilization of SeNPs.

\section{XRD analysis}

XRD pattern of SeNPs studied is portrayed in Figure 4, where the diffraction intensity was observed from $2 \theta$ angles varying from $10^{\circ}$ to $100^{\circ}$. The distinct peak at $23.2^{\circ}, 29.5^{\circ}, 45.5^{\circ}, 55.5^{\circ}$ and $59.8^{\circ}$ determined the crystalline nature of SeNPs.

\section{SEM analysis}

Scanning electron microscopy (SEM) is widely used for inspecting the particles morphology, i.e. to determine the physical dimensions, shapes and size distribution of nanoparticles. Result obtained revealed that the morphological characteristics of biosynthesised SeNPs by propolis extract was found to be oval in shape with a smooth surface and the size ranged from 52.9-118 $\mathrm{nm}$ (Figure 5).

\section{Antimicrobial activity}

Antibacterial potential of SeNPs biosynthesised from Karnataka propolis sample was evaluated according to colour change against the bacterial strains such as Staphylococcus aureus, Bacillus cereus, Streptococcus mutans, Escherichia coli, Salmonella typhi and Pseudomonas aeruginosa by resazurin microtiter plate method and summarised in Table 1. Results revealed that, an antibacterial potential of SeNPs sample showed a significant antibacterial activity against 4

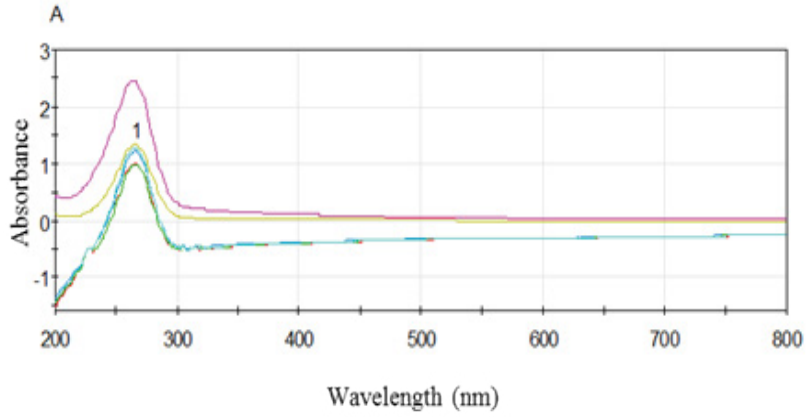

Figure 2: UV-visible spectrum of selenium nanoparticles biosynthesised from ethanolic extract of propolis obtained from different states.

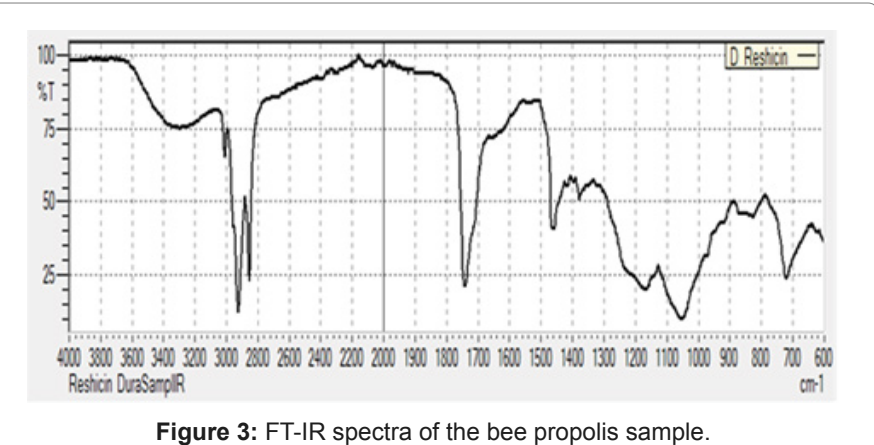

Figure 3: FT-IR spectra of the bee propolis sample.

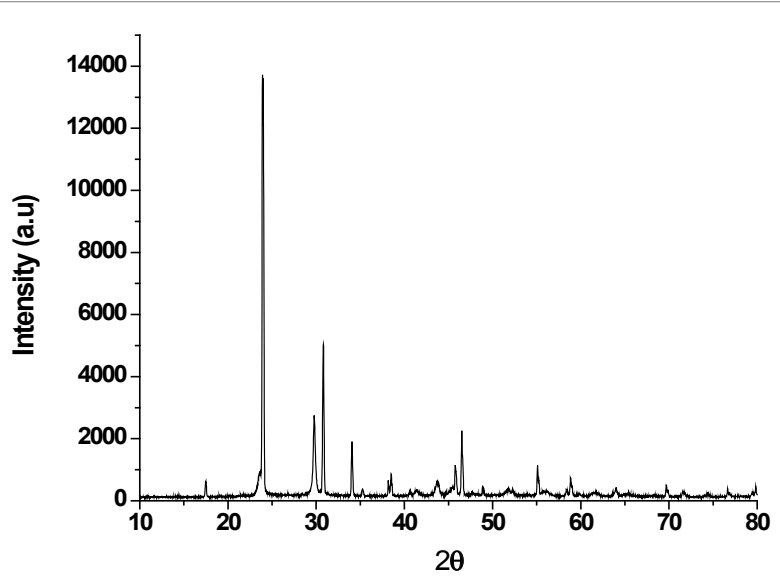

Figure 4: X-ray diffraction pattern of biosynthesised selenium nanoparticles.

bacterial strains. Highest antibacterial activity was observed against Bacillus cereus and Staphylococcus aureus (gram-positive bacteria) at a concentration of $250 \mu \mathrm{g} / \mathrm{ml}$. The moderate activity was observed against Streptococcus mutans (gram-positive bacteria) followed by Salmonella typhi (gram-negative bacteria) at the concentration of $500 \mu \mathrm{g} / \mathrm{ml}$ and $1000 \mu \mathrm{g} / \mathrm{ml}$ respectively. SeNPs did not inhibit the growth of Escherichia coli and Pseudomonas aeruginosa up to the highest concentration of 1000 $\mu \mathrm{g} / \mathrm{ml}$. The antifungal effect of SeNPs was evaluated against Aspergillus niger, Aspergillus flavon and Candida albicans by well diffusion method. Maximum zone of inhibition was found in Aspergillus niger (20 mm) followed by Aspergillus flavous ( $18 \mathrm{~mm}$ ) at $500 \mu \mathrm{g} / \mathrm{ml}$ concentration, where as Candida albicans did not show any significant zone of inhibition (Table 2). 


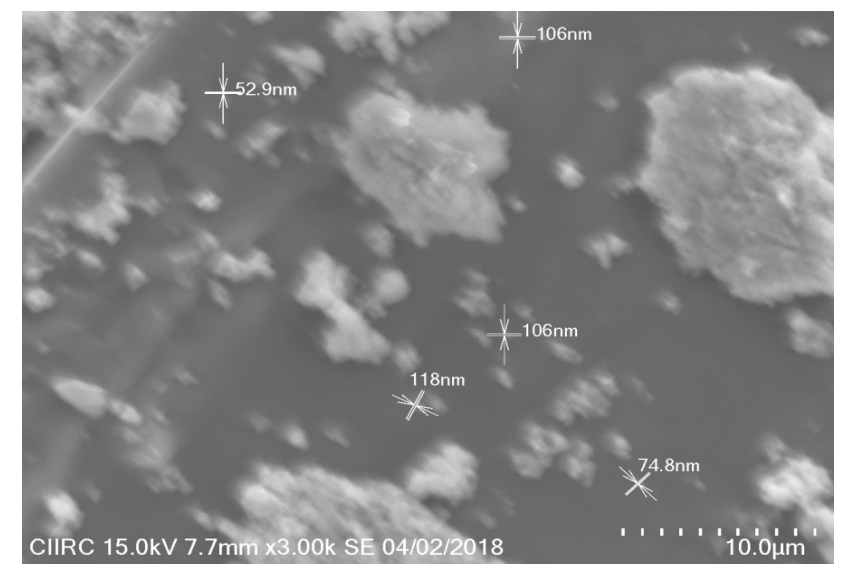

Figure 5: Scanning electron microscopy image showing the morphology and size of nanoparticles.

\begin{tabular}{|c|c|c|}
\hline SI. No. & Test organisms & $\begin{array}{c}\text { Minimum Inhibition Concentration (MIC) } \\
\text { of SeNPs }(\boldsymbol{\mu g} / \mathbf{m l})\end{array}$ \\
\hline 1. & Bacillus cereus & 250 \\
\hline 2. & Escherichia coli & 000 \\
\hline 3. & Salmonella typhi & 1000 \\
\hline 4. & Pseudomonas aeruginosa & 000 \\
\hline 5. & Staphylococcus aureus & 250 \\
\hline 6. & Streptococcus mutans & 500 \\
\hline
\end{tabular}

Table 1: In vitro antibacterial activity of ethanol extract of propolis by resazurin microtiter plate method.

\begin{tabular}{|c|c|c|c|c|}
\hline \multirow[b]{2}{*}{ SI. No. } & \multirow{2}{*}{$\begin{array}{c}\text { SeNPs } \\
\text { Concentrations }\end{array}$} & \multicolumn{3}{|c|}{ Fungal Zone of Inhibition (mm) } \\
\hline & & $\begin{array}{l}\text { Aspergillus } \\
\text { niger }\end{array}$ & $\begin{array}{l}\text { Aspergillus } \\
\text { flavous }\end{array}$ & $\begin{array}{l}\text { Candida } \\
\text { albicans }\end{array}$ \\
\hline 1. & $100 \mu g$ & 10 & 9 & 9 \\
\hline 2. & $200 \mu \mathrm{g}$ & 11 & 9 & 9 \\
\hline 3. & $300 \mu \mathrm{g}$ & 13 & 9 & 9 \\
\hline 4. & $400 \mu \mathrm{g}$ & 15 & 10 & 9 \\
\hline 5. & $500 \mu \mathrm{g}$ & 20 & 18 & 9 \\
\hline 6. & Ethanol & 00 & 00 & 00 \\
\hline 7. & Cycloheximide & 22 & 22 & 18 \\
\hline
\end{tabular}

Table 2: In vitro antifungal activity of ethanol extracts of propolis by well diffusion method.

\section{Discussion}

Although the previous report on biosynthesis of SeNPs using plant extract [37] and microorganisms [38] are available, there is a lack of scientific literature on biosynthesis of SeNPs mediated by propolis extract. Hence, this report gives an alternative approach for biosynthesis of SeNPs using an ethanol extract of propolis. The reduction of selenium ions into SeNPs induced by propolis extracts was confirmed by the conversion of color from light brown to reddish orange after the addition of acidic sodium selenite solution which is the most significant property of nanoparticles. Result is in accordance with the previous report [39] on synthesis of SeNPs mediated by aqueous extract of Aloe vera leaf. Present results also correlates with UV-visible spectra of SeNPs biosynthesised from the aqueous extract of orange peel and Petroselinum crispum leaf showed the peak at 265.5-270 nm respectively $[40,41]$.

The functional group such as alcohol and polyphenols involved in the reduction of selenium ion to SeNPs were detected with FT-IR analysis. Recent reports on synthesis of SeNPs by the aqueous extract of Leucas lavandulifolia leaf, Bougainvillea spectabilis flower and dried Vitis vinifera fruits highlighted the probable role of phytochemicals such as terpenoids, sugar, amines, alcohols, phenols and carboxylic acids in reduction of selenium ions and stabilisation of SeNPs [4244]. X-ray diffraction is an effective technique used to characterise the nanoparticles. Present results confirmed the biosynthesised SeNPs were in the form of nanocrystals, which corresponds to the reported data of biosynthesised SeNPs mediated by Diospyros montana leaf extract [45]. Size of the biosynthesised SeNPs was analysed by scanning electron microscopy. Size of nanoparticles has a significant effect on the UVvis absorption spectra, i.e. small size particles absorb light of a lower wavelength and vice versa [46]. The particles were found to be oval shaped with diameter range of 52.9-118 $\mathrm{nm}$. The present observation is in accordance with the report [47] where Bacillus mycoides, isolated from the rhizosphere of legume Astragalus bisulcatus was used to synthesise SeNPs by reducing sodium selenite with size range of 50$400 \mathrm{~nm}$. Similarly, the shape of SeNPs synthesised from fenugreek seed extract in aqueous medium was oval in shape with smooth surface, but the size ranging from $50-150 \mathrm{~nm}$. They have been found to be active against human breast cancer cells [48]. There is a clear correlation between the nanoparticles size and their biological activity [49]. Thus, these reports clearly justify the efficient synthesis and stabilisation of SeNPs from the ethanol extract of propolis.

The radical scavenging activity of ethanol extract of propolis was found to be concentration dependent, the activity increased with increasing concentrations. Ethanol extracts showed a comparable ABTS, DPPH, FRAP and SOD radical scavenging activities with gallic acid as a standard [50]. However, the propolis samples collected from Karnataka exhibited an effective radical inhibition in all the assays compared to other states. SeNPs are less toxic form of selenium, has been proved to have antioxidant activity and is being used as chemopreventive agent in cancer treatment [39]. Nanoparticles are endorsed as sustainable antimicrobial agents having remarkable perspective to resolve the microbial multidrug resistance problem [51,52] and microbial biofilm formation [12,53]. Resazurin microtiter plate method has provided a potentially useful technique for determining maximum inhibitory concentration (MIC) of a large number of test samples. MIC in microbiology is the lowest concentration of antimicrobials that will inhibit the visible growth of microorganisms after required incubation. It is important in diagnostic laboratories to confirm resistance of microorganisms to an antimicrobial agents and also to monitor the activity of new antimicrobial agent [54,55]. Resazurin is blue compound, has been potentially used for a novel antibacterial therapy where the active bacterial cells reduce the non-fluorescent resazurin (blue) to the fluorescent resorufin (pink) which can be further reduced to hydroresorufin [56]. The biogenic nanoparticles have been found to be active against a wide range of gram-positive and gram-negative bacteria [57-61]. According to the results of the present study, it is observed that the increasing quantity of SeNPs have comparatively higher antibacterial activity against Staphylococcus aureus and Bacillus subtilis probably due to thinner peptidoglycan layer and presence of porins [62]. From the present results, it is indicated that the biosynthesised SeNPs mediated by propolis extract has the efficient antioxidant and antimicrobial activity against pathogenic organisms. The antifungal activity of SeNPs extract was enhanced by increasing the concentration, confirming the inhibition activity of the extract was concentration dependent. Furthermore, the antifungal activity of standard antifungal cycloheximide was more potent than the biosynthesised SeNPs extract against tested organisms in the present study [63]. However, much work is needed to control the morphology 
Citation: Shubharani R, Mahesh M, V.N.Yogananda Murthy (2019) Biosynthesis and Characterization, Antioxidant and Antimicrobial Activities of Selenium Nanoparticles from Ethanol Extract of Bee Propolis. J Nanomed Nanotechnol 10: 522. doi: 10.4172/2157-7439.1000522

Page 6 of 7

and particle size, important issues in the evaluation of nanoparticle synthesis.

\section{Conclusion}

The SeNPs can be used for various applications especially in medicine, due to its medicinal properties such as low toxicity, better reactivity, low dosage, etc. The formation of SeNPs and their functionalization with ethanol extract of bee propolis were evident from UV-vis. Spectra, XRD, FT-IR and SEM images. Metabolites from propolis extracts i.e alcohol and phenolic compounds were predominantly responsible for the reduction of selenium ion to SeNPs. The biosynthesized SeNPs shows oval shape with a smooth surface and the size range of 52.9-118 nm. SeNPs exhibited significant activity against antioxidant properties, gram-positive and gram-negetive bacterial and fungal strains. The biosynthesized SeNPs could be a potent antioxidant and antimicrobial agent to treat diseases caused by gram-positive and fungal strains may be used to kill the pathogens for preventing diseases. Antioxidant assays of all the propolis samples studied indicated that, the propolis extract collected from Karnataka showed a significant radical scavenging activity. However, further research is needed to improve the synthesis efficiency, control of particle size and its application in medicine and healthcare.

\section{Conflict of Interest}

All the authors declare that they have no conflict of interest.

\section{References}

1. Duran N, Marcato PD, Duran M, Yadav A, Gade A, et al. (2011) Mechanistic aspects in the biogenic synthesis of extracellular metal nanoparticles by peptides, bacteria, fungi and plants. Appl Microbiol Biotechnol 90: 1609-1624.

2. Ankush S, Amit K Goyal, Gautam R (2017) Recent Advances in Metal Nanoparticles in Cancer Therapy. J Drug Target 26: 1-45.

3. Seong JK, Allen JB (2012) DNA Analysis by Application of Pt Nanoparticle Electrochemical Amplification with Single Label Response. J Amer Chem Soc 134: 10777-10779.

4. Adeyemi OS, Sulaiman FA (2015) Evaluation of metal nanoparticles for drug delivery systems. J Biomed Res 29: 145-149.

5. Goncalo D, Joao C, Bruno V, Leticia G, Maria A, et al. (2012) Noble metal nanoparticles for biosensing applications. Sensors 12: 1657-1687.

6. Conroy S, Jerry SHL, Miqin Z (2008) Magnetic nanoparticles in MR imaging and drug delivery. Adv Drug Deliv Rev 60: 1252-1265.

7. Ashish Khandelwal, Ritika Joshi (2018) Synthesis of nanoparticles and their application in agriculture. Acta Scientific Agriculture 2: 10-13.

8. Vaseashta A, Vaclavikova M, Vaseashta S, Gallios G, Roy P, et al. (2007) Nanostructures in environmental pollution detection, monitoring and remediation. Sci Technol Adv Mat 8: 47-59.

9. Gadad AP, Vijaykumar SV, Dandagi PM, Bolmol UB, Pavani Pallavi N (2014) Nanoparticles and their therapeutic application in pharmacy. Int J Pharm Sci Nanotech 7: 2509-2519.

10. Isao Matsui (2005) Nanoparticles for electronic device applications: A brie review. J Chem Eng Jpn 38: 535-546.

11. Mohanpuria P, Rana NK, Yadav SK (2008) Biosynthesis of nanoparticles: technological concepts and future applications. J Nanopart Res 10: 507-517.

12. Mallevere F, Fernandes TF, Aspray TJ (2016) Pseudomonas putida biofilm dnamics following a single pulse of silver nanoparticles. Chemosphere 153: 356-364.

13. Seo WS, Lee JH, Sun X, Suzuki Y, Mann D, et al. (2006) FeCo/graphitic-shell nanocrystals as advanced magnetic-resonance-imaging and near-infrared agents. Nat Mater 5: 971-976.

14. Minaev VS, Timoshenkov SP, Kalugin VV (2005) Structural and phase transformations in condensed selenium. J Optoelectron Adv Mat 7: 1717-1741.
15. Dick DM, Agrawal A (2003) The genetics of alcohol and other drug dependence. Alcohol Res Health 31: 111-118.

16. Chiou YD, Hsu YJ (2011) Advances in nanotechnology research and application: 2012 Ed. Appl Cataly Environ B 105: 211-219.

17. Yang L, Shen Y, Xie A, Liang J (2007) Oriented attachment growth of threedimensionally packed trigonal selenium microspheres into large area wire networks. Eur J Inorg Chem 28: 4438-4444.

18. Torres SK, Campos VL, Leon CG, Rodrıguez-Llamazares SM, Rojas SM, et al. (2012) Biosynthesis of selenium nanoparticles by Pantoea agglomerans and their antioxidant activity. J Nanopar Res.

19. Shahverdi AR, Fakhimi A, Mosavat G, Fesharaki PJ, Rezaie SM, et al. (2010) Antifungal activity of biogenic selenium nanoparticles. World Appl Sci J 10: 918-922.

20. Tugarova AV, Kamnev AA (2017) Proteins in microbial synthesis of selenium nanoparticles. Talanta 174: 539-547.

21. Visha P, Nanjappan K, Selvaraj P, Jayachandran S, Elango A, et al. (2015) Biosynthesis and structural characteristics of selenium nanoparticles using Lactobacillus acidophilus bacteria by wet sterilization process. Int J Advan Veter Sci Technol 4: 178-183.

22. Harikrishnan H, Naif Abdullah A, Ponmurugan K, Shyam Kumar R (2012) Microbial synthesis of selinium nanocomposite using saccharomyces cerevisiae and its antimicrobial activity against pathogens causing nosocomial infection. Chalcogenide Lett 9: 509-515

23. Miguel MG (2013) Chemical and biological properties of propolis from the western countries of the mediterranean basin and Portugal. Int J Pharm Pharm Sci 5: 403-409.

24. Shubharani Ramnath (2017) Synthesis of copper nanoparticles from bee propolis extract and its antibacterial property. Eur J Pharm Med Res 4: 684-688.

25. Padil VVT, Cernik M (2013) Green synthesis of copper oxide nanoparticles using gum karaya as a biotemplate and their antibacterial application. Int $J$ Nanomed 8: 889-898.

26. Mihai CM, Marghitas L Al (2010) Antioxidant capacity of transylvanian Propolis. Bull UASVM Anim Sci Biotechnol 67: 132-138

27. Re R, Pellegrini N, Proteggente A, Pannala A, Yang M, Rice-Evans C (1999) Antioxidant activity applying an improved ABTS radical cation decolorization assay. Free Radic Biol Med 26: 1231-1237.

28. Goyal AK, Middha SK, Sen A (2010) Evaluation of the DPPH radical scavenging activity, total phenols and antioxidant activities in Indian wild Bambusa vulgaris "Vittata" methanolic leaf extract. J Nat Pharma 1: 40-45.

29. Pulido R, Bravo L, Sauro-Calixo F (2000) Antioxidant activity of dietary polyphenols as determined by a modified ferric reducing/antioxidant power assay. J Agri Food Chem 48: 3396-3402.

30. Arun Kumar, Som Dutt, Ganesh Bagler, Paramvir Singh Ahuja, et al. (2012) Engineering a thermo-stable superoxide dismutase functional at sub-zero to $>50^{\circ} \mathrm{C}$, which also tolerates autoclaving. Sci Rep 2: 387 .

31. Ramamurthy $\mathrm{CH}$, Sampath KS, Arunkumar $\mathrm{P}$, Suresh Kumar M, Sujatha V, et al. (2013) Green synthesis and characterization of selenium nanoparticles and its augmented cytotoxicity with doxorubicin on cancer cells. Bioprocess Biosyst Eng 36: 1131-1139.

32. Padalia H, Moteriya P, Chanda S (2015) Green synthesis of silver nanoparticles from marigold flower and its synergistic antimicrobial potential. Arab J Chem 8 732-741.

33. Sun S, Murray C, Weller D, Folk L, Moser A (2000) Monodisperse FePt nanoparticles and ferromagnetic FePt nanocrystal super lattices. Sci 287 : 1989-1992.

34. Dekkers S, Krystek P, Peters RJ, Lankveld DP, Bokkers BG, et al. (2011) Presence and risks of nanosilica in food products. Nanotoxicol 5: 393-405.

35. Karuppusamy S, Rajasekaran KM (2009) High throughput antibacteria screening of plant extracts by Resazurin Redox with special reference to medicinal plants of Western Ghats. Glob J Pharma 3: 63-68.

36. Varaprasad Bobbarala, Prasanth Kumar Katikala, Chandrasekhar Naidu K Somasekhar Penumajji (2009) Antifungal activity of selected plant extracts against phytopathogenic fungi Aspergillus niger F2723. Ind J Sci Technol 2: $87-90$ 
Citation: Shubharani R, Mahesh M, V.N.Yogananda Murthy (2019) Biosynthesis and Characterization, Antioxidant and Antimicrobial Activities of Selenium Nanoparticles from Ethanol Extract of Bee Propolis. J Nanomed Nanotechnol 10: 522. doi: 10.4172/2157-7439.1000522

37. Kavitha KS, Baker S, Rakshith D, Kavitha HU, Yashwantha Rao HC, et al. (2013) Plants as green source towards synthesis of nanoparticles. Int Res J Biol Sci 2: 66-76

38. Fesharaki PJ, Nazari P, Shakibaie M, Rezaie S, Banoee M, et al. (2010) Biosynthesis of selenium nanoparticles using Klebsiella pneumoniae and their recovery by a simple sterilization process. Braz J Microbiol 41: 461-466.

39. Jay Vyas, Shafkat Rana (2017) Antioxidant activity and biogenic synthesis of selenium nanoparticles using the leaf extract of aloe vera. Int J Curr Pharma Res 9: 147-152.

40. Sasidharan S, Sowmiya R, Balakrishnaraja R (2015) Biosynthesis of selenium nanoparticles using citrus reticulata peel extract. World J Pharm Res 4: 1322 1330.

41. Luminita Fritea, Vasile Laslo, Simona Cavalu, Traian Costea, Simona loana Vicas (2017) Green biosynthesis of selenium nanoparticles using Parsley (Petroselinum Crispum) leaves extract. Studia Universitatis "Vasile Goldiş". Seria Ştiinţele Vieţii 27: 203-208.

42. Kirupagaran R, Saritha A, Bhuvaneswari S (2016) Green synthesis of selenium nanoparticles from leaf and stem extract of Leucas lavandulifolia $\mathrm{Sm}$. and their application. J Nanosci Technol 2: 224-226.

43. Deepa B, Ganesan V (2015) Biogenic synthesis and characterization of selenium nanoparticles using the flower of Bougainvillea spectabilis Willd. In J Sci Res 4: 690-695.

44. Sharma G, Sharma AS, Bhavesh R, Park J, Ganbold B, et al. (2014) Biomolecule-mediated synthesis of selenium nanoparticles using dried vitis vinifera (Raisin) extract. Molecules 19: 2761-2770.

45. Karuppannan K, Nagaraj E, Sujatha V (2017) Diospyros montana leaf extractmediated synthesis of selenium nanoparticles and their biological applications. New J Chem 41: 27

46. Amit Kumar Mittal, Abhishek Kaler, Aparna Vasant Mulay, Uttam Chand Banerjee (2013) Synthesis of gold nanoparticles using whole cells of Geotrichum candidum. J Nanopart.

47. Lampis S, Zonaro E, Bertolini C, Bernardi P, Butler CS, et al. (2014) Delayed formation of zero-valent selenium nanoparticles by Bacillus mycoides SelTE01 as a consequence of selenite reduction under aerobic conditions. Microb Cell Fact 13: 35-49.

48. Prasad KS, Selvaraj K (2014) Biogenic synthesis of selenium nanoparticles and their effect on As(III)-induced toxicity on human lymphocytes. Biol Trace Elem Res 157: 275-283.

49. Hassanin KMA, Abd El-Kawi SH, Hashem KS (2013) The prospective protective effect of selenium nanoparticles against chromium-induced oxidative and cellular damage in rat thyroid. Int J Nanomed 8: 1713-1720.
50. Benzie IF, Strain JJ (1996) The ferric reducing ability of plasma (FRAP) as a measure of 'antioxidant power' the FRAP assay. Anal Biochem 239: 70-76.

51. Franci G, Falanga A, Galdiero S, Palomba L, Rai M, et al. (2015) Silver nanoparticles as potential antibacterial agents. Molecules 20: 8856-8874.

52. Rai MK, Deshmukh SD, Ingle AP, Gade AK (2012) Silver nanoparticles: the powerful nanoweapon against multidrug-resistant bacteria. J Appl Microbio 112: $841-852$

53. Mohan S, Oluwafemi OS, George SC, Jayachandran VP, Lewu FB, et al (2014) Completely green synthesis of dextrose reduced silver nanoparticles, its antimicrobial and sensing properties. Carbohydr Polym 106: 469-474

54. Das K, Tiwari RKS, Shrivastava DK (2010) Techniques for evaluation of medicinal plant products as antimicrobial agent: Current methods and future trends. J Med Plant Res 4: 104-111.

55. Honary S, Barabadi H, Fathabad EG, Naghibi F (2012) Green synthesis of copper oxide nanoparticles using Penicillium aurantiogriseum, Penicillium citrinum and Penicillium wakasmanii. Dig J Nanomater Biostruct 7: 999-1005.

56. Bauer J, Siala W, Tulkens PM, Van Bambeke F (2013) A combined pharmacodynamic quantitative and qualitative model reveals the potent activity of daptomycin and delafloxacin against Staphylococcus aureus biofilms. Antimicrob Agents Chemother 57: 2726-2737.

57. Morones JR, Elechiguerra JL, Camacho A, Holt K, Kouri JB, et al. (2005) The bactericidal effect of silver nanoparticles. Nanotechnol 16: 2346-2353.

58. Birla SS, Tiwari VV, Gade AK, Ingle AP, Yadav AP (2009) Fabrication of silver nanoparticles by Phoma glomerata and its combined effect against Escherichia coli, Pseudomonas aeruginosa and Staphylococcus aureus. Lett Appl Microbio 48: 173-179.

59. Priyaragini S, Sathishkumar SR, Bhaskararao KV (2013) Biosynthesis of silver nanoparticles using actinobacteria and evaluating its antimicrobial and cytotoxicity activity. Int J Pharm Pharm Sci 5: 709-712.

60. Anasane N, Golinska P, Wypij M, Rathod D, Dahm H, et al. (2016) Acidophilic actinobacteria synthesised silver nanoparticles showed remarkable activity against fungi-causing superficial mycoses in humans. Mycoses 59: 157-166.

61. Wypij M, Golinska P, Dahm H, Rai M (2017) Actinobacterial-mediated synthesis of silver nanoparticles and their activity against pathogenic bacteria. IET Nanobiotechnol 11:336-342.

62. Jay Vyas, Shafkat Rana (2018) Synthesis of selenium nanoparticles using Allium sativum extract and analysis of their antimicrobial property against gram positive bacteria. The Pharm Innov J 7: 262-266.

63. Zhang JS, Gao XY, Zhang LD, Bao YP (2001) Biological effects of a nano red elemental selenium. BioFactors 15: 27-38. 